МАРКОВ Александр Викторович доктор филологических наук, профессор кафедры кино и современного искусства Российского государственного гуманитарного университета,

Москва, Российская Федерация Alexander V. MARKOV

Dr. Sci. (Theory of Literature. Textology), Prof., Russian State University for the Humanities, Moscow, Russian Federation, markovius@gmail.com

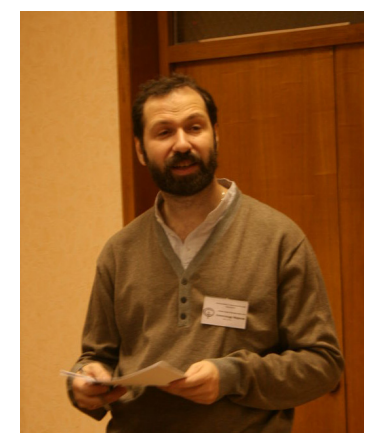

\section{Природное наследие Юга России в поэзии Виктора Кривулина и Светланы Кековой}

\section{The Natural Heritage of Southern Russia in the Poems by Viktor Krivulin and by Svetlana Kekova}

В статье на примере творчества двух видных поэтов религиозно-метафизического направления раскрываются особенности динамического противопоставления северной и южной природы. Данные поэтические открытия, обновляющие как привычную образность южнорусской природы, так и жанровую систему, оказываются значимыми для понимания того, как складывается цельный образ общероссийского природного наследия в новейшей русской литературе. Противопоставление северной и южной природы у этих поэтов из статического становится динамическим, что размывает привычные границы лирическихжанров и позволяет воспринять ландшафт как часть экзистенциального переживания. Обращение к традициям обживания этого ландшафта придает вертикальное измерение идеям и практикам сбережения локального природного наследия. Метод близкого чтения показал, как работает поэтическое воображение, являющееся важным эвристическим инструментом понимания ландшафта как динамики длящегося экзистенциального выбора.

Ключевые слова: ландшафт, пейзажная лирика, экфрасис, имажинарий, иконичность, поэтическое воображение, южная природа, юг России, религиозная метафизика.

Отражение в поэзии природного наследия юга России не всегда подчиняется простому противопоставлению севера и юга, при всей его выразительности. Более того, есть поэтические системы, отводящие подобному натуралистически понимаемому противопоставлению не столь существенную роль, как осмыслению природы наследия, для которого 
северность или южность - аспекты его бытия, но не единственное содержание впечатлений. Такие системы можно назвать метафизическими: они интересуются сутью вещей, тогда как картографирование мира, в котором располагаются вещи, служит не окончательному выводу о вещах, а, наоборот, началу новых размышлений о том, как в этих вещах сочетаются традиция и современность, время и мгновение вечности.

Вопрос о том, что маркеры южной русской природы не просто вводят новые лирические оппозиции, но модифицируют поэтическое высказывание о русской природе как таковой и соответствующий набор лирических стратегий в описании ландшафтов и границ национальной культуры, уже обсуждается в науке [1]. Одним из ключей для отечественной науки здесь оказалось творчество А. Платонова, повлиявшее на метафизические поиски всей дальнейшей русской литературы, в нем возможность построения ландшафта напрямую связана с возможностью реорганизации речи и отрешения ее от традиционных клише пространственного опыта [2, с. 84].

Мы опираемся на опыт близкого чтения природно-ландшафтных стихов, в частности, обоснованный в стихотворении «Заморозки» Б. Пастернака [4]. Кроме того, мы учитываем достижения современных исследований географического воображения (см. [3]), показывающие, что в лирической поэзии оно становится частью рефлексии над возможностью лирического произведения приобретать дополнительную ценностную оптику и оценивать ландшафт как необходимое культурное наследие, нуждающееся в экзистенциальном внимании.

В трактовке религиозно-метафизической поэзии мы исходим из той аналитики репрезентативности, которая уже проделана в науке, указывающей, при каких условиях ландшафт может стать иконичным и райским и как это снимает часть и географических, и жанровых оппозиций на путях новой гармонии [8, с. 137], а также при каких условиях возможно то размывание границ лирических жанров внутри литургической интенции поэзии, когда и переживание предметов оказыва- ется предельно динамическим и ритуальным [5, с. 58]. Мы при этом исходим не из анализа устойчивой образности, а из того, как вообе мыслимо наследие в лирическом высказывании, устремленном вертикально, к экзистенциальным вопросам, и как эта мысль становится необходимой просто для того, чтобы высказывание состоялось и осуществились очевидные для внимательного читателя его границы, а не только границы изображаемого. Поэтому религиозно-метафизическая поэзия обращается не только к вещам, но и к жанрам, как пейзаж, так как познание границ и мер оказывается не только художественной, но и духовной задачей.

Обычные представления о юге России как о курорте или месте комфортного пребывания, нормативные в советской поэзии и служащие основой уже драматических или фельетонных сюжетов, не свойственны религиозно-метафизической поэзии. Слово «отдых» в религиозно-метафизической поэзии почти не употребляется. Одно из немногих исключений - стихотворение Кривулина «Студенты империи» (2000), посвященное европейскому, а не русскому югу и представляющее собой развертывание правила Суворова «Тяжело в учении - легко в бою», где переход через Альпы вслед за Суворовым отождествляется с отдыхом и с паузой в речи, с необходимым созерцанием окружающего мирапосле долгого риторического обоснования педагогической миссии.

В стихотворении «Летняя рекреация» (2000) описывается условный юг страны: такие приметы, как множественные пивные фестивали в июне (то есть когда отпускное время наступает в нашей стране, в Европе еще работают, и пивные фестивали, за исключением Бельгии, обычно проходят гораздо позже), аренда жилья людьми почти без денег, скудость развлечений, ограниченных в основном загоранием на пляже, говорит, что перед нами наша страна лихих 1990-х:

июнь с пивными фестивалями юг арендуемый (но в долг)

поволновался и умолк

народец вечно раздеваемый 
Жалобы на южные цены, высказанные по-русски (за границей вряд ли они были бы уместны, да и «народцем» назвать отдыхающих за границей тогда было нельзя), сменились простым отдыхом. Далее этот южный отдых оказывается кратковременным, даже если погода «тихая» и можно загорать сколько угодно, стекаясь на пляжи:

его берет погодка тихая

за шиворот и он потек

и много ль времени натикало

в его нестиранный платок

Платок, которым вытирают слезы, оказывается мерой времени. Объяснить этот смелый образ можно только обратившись к финальным двум строкам стихотворения:

уже не знает и не ведает

но отдыхает от себя

в садах с ампирными лафетами

с решетками и парапетами

где еле языком ворочая

скативши глазоньки в кулек

гуляет совесть нерабочая

не рубящая уголек

Пейзаж «рекреации», постсоветского курорта, может быть и Крымом, и Новороссийском, любым местом, где есть памятники, напоминающие о войнах николаевского времени. Термин «ампир» относится к наполеоновскому стилю, и его подражаниям, в том числе в России Александром I и Николаем I, и поэтому он напоминает скорее о драматизме войн XIX в., чем о триумфе русского оружия в XVIII в. При этом пейзаж построен как экфрасис рисунка, открытки или, скорее всего, фотографии: в советское время любительские фотографии делались на пляже, но фотографии для семейного альбома или отправки родственникам в парках, лицензированными фотографами. Смешивая дореволюционное, советское и постсоветское, Кривулин изображает южную природу как место забвения. Для Кривулина вообще образ «курорта» был связан с образом фотографий, но при этом не гарантирующих благополучие человека, не защищающих его от катастрофы, как мы видим это в стихотворении «Ссыльный» (1995), где ученый, оказавшийся в среднеазиатской ссылке, продолжает рассылать открытки с альпийскими видами, оставшиеся, по всей видимости, от стажировок. Этот ученый вполне адаптировался к условиям ссыльного, и даже публикует свои выводы «в межрайонной газете», и он отомстит тем, что правильно поймет филологические закономерности отношения китайской и среднеазиатской культур, правильно пересоберет мировую историю. Мы встречаем слово «межрайонный», не просто пародирующее бюрократический жаргон, но указывающее на преимущество «воображаемой географии», собирающей разнообразие культур и районов в одно понятие, над реальной географией. Кривулин ставит эксперимент: что будет дальше после этой сборки?

Последние две строфы содержат цитаты из советской поэзии: «не зная» и «не ведая»весьма частое парное выражение в позднесоветской поэзии, тогда как «не рубящая уголек» - полуцитата из стихотворения Е. Евтушенко «Разговор с Кузьмой Севериновым»:

Я скажу по-донбасски:

От стихов я далек,

Но ты тоже долбаешь

Как и я, уголек.

Довольно тонкий ассонанс Евтушенко, «донбасски - долбаешь», в духе изощренной грубости Маяковского, должен был показать, что шахтер не просто понимает поэта, а обладает не меньшей современной поэтической культурой, условность «разговора» превращалась в реализацию идеи народной поэзии. Кривулин во многих стихах относится к этой идее скептически: признавая тонкость народного понимания, он не допускает, что поэтическая речь будет вполне ясна. Ведь для Кривулина, начиная с его хрестоматийных ранних стихов, как «Я Тютчева спрошу...», «Клио» или «Кассандра», поэзия сближается с пророчеством об истории, непонятным даже самому поэту, не говоря уже о публике.

Интересно, что «рубящая» может быть и отсылкой к жаргонному «врубиться», иначе говоря, намеком на отсутствие диалога меж- 
ду поэтом и рабочим, в отличие от описанной Евтушенко ситуации, и указанием на то, что Кривулин взял цитату не из первых рук в эссе 0. Седаковой «Другая поэзия» эти строки цитируются по памяти [7, с. 228], с заменой ассонанса на тень ассонанса «кузбасски - рубаешь». Седакова видит в таком подходе прагматизацию поэзии, превращение ее в инструмент воздействия на социальную реальность, сопоставляя ее на этом основании с обрядовым фольклором, но в фольклоре видя преимущество - чувство уместности, проявляющееся на разных уровнях поэтического текста (Седакова - структуралист по выучке).

В русской религиозно-метафизической поэзии за противопоставлением севера и юга были закреплены свои созвездия - Большая Медведица и Кассиопея соответственно. Так, в стихотворении Седаковой «Ночное шитье» (1980) противопоставляется созвездие Кассиопеи, предвещающее солнечное тепло и торжество («И Кассиопеи бледнеет орлица» - указывается не только часть созвездия, но и общая идея царственного торжества), и созвездия Большой и Малой Медведиц, названные «колесницами». «Я звездного неба люблю колесницы» - это чувство сопровождает «ночное шитье», понятое как аскетическая работа, включающая и у Седаковой, и у всех религиозных метафизиков умение терпеть любой холод перед восходом нового солнца, Царствия Небесного: «Мы выткем то небо, что ходит за мною». У Кековой в стихотворении «Размышления над картой звездного неба» (1986) так же точно Кассиопея оказывается началом движения, олицетворенного и Меркурием (Ртутью), и молоком млечного пути, питающим все мироздание:

но в это время в небе виден след ползущего куда-то скарабея.

Он катит шар перед собой, как ртуть, туда, где ниц лежит Кассиопея и неживую обнажает грудь, откуда вечно Путь струится Млечный, безмерно сладкий, мертвый,

бесконечный.

Созвездия названы неживыми и мертвыми, как небесные тела, но при этом катить шар - это и означает длить жизнь и сопротивляться смерти, это частый образ пряжи и клубка и у Седаковой, утверждающей этот образ как противоположность нити Парок, как христианский ответ на языческий фатализм. И так же точно Кекова вводит многообразие образов движения, движения, приводящее в движение ртуть, как противостояние былой смерти. Юг оказывается и местом, где любое движение оставляет след, а не пропадает среди льда и снега, и где струящийся путь вмещает в себя бесконечное число предметов.

Интересно стихотворение Кривулина «Враги» (2000), вроде бы посвященное преступникам и нищим 1990-х. Но оно представляет этих выходцев с юга как красавцев; их выход на промысел лунной ночью подобен сиянию звезд, вероятно, южных звезд, но при этом они попрошайничают и грабят с объявленной целью купить «билет до Ростова», вернуться в свою преступную столицу из заснеженных краев в южные.

Уже не астрономическое, а ландшафтное изображение юга мы встречаем в стихотворении Кривулина «Вслед за тройкой», очевидно, указывающее на предполагаемый маршрут гоголевского Чичикова в Новороссию, где он должен был поселить своих мертвых душ. В начале деятельность Чичикова и его бегство вдруг связываются и с эстетикой боевика, перестрелки на киноэкране, и с забвением:

\section{пули птицей полетели вслед за полевой за тройкой - не догнать конца недели не прогнать тоски настойкой}

Но неожиданно появляется образцовый пейзаж юга России, включающий весь минимум опознаваемых примет, в том числе развитое коневодство:

степь рожающая горы ширь забитая в теснину оттого здесь кони скоры что вокруг едят конину

Кривулин, петербуржец, явно отличается от Кековой, для которой горный ландшафт - не экзотический, а с детства знако- 
мый. Благодаря этимологизированию родного города Саратова - Желтой Горы - этот город оказывается «узкоглазый и китайский» («Надо мною жук летает майский...», 1999), он становится местом проклятой доли: «мой дом прокаженный на Желтой горе», противопоставленной литургическому спасению («Возьми же муки для лепешек квасных, посуду для прочих даров», 1999). Этот южный природный ландшафт, который как будто сам приходит в движение, сам себя порождает и сам себя поглощает, оказывается и ландшафтом коневодства и питания кониной. По сути, Кривулин моделирует юг как самораскрывающийся, пишущий себя экфрасис, так что потом и оказывается, что могут преодолеваться не только ландшафтные границы, но и границы внутреннего и внешнего.

\section{бел-поток шипя в каменьях вывернулся весь наружу - а нутро́-то в черных змеях в язвах измотавших душу.}

Такая перемена полностью следует из того, что в тройке сидит Чичиков, как и положено в произведениях Гоголя, просторы юга раскрываются как фантасмагорические декорации. Но Чичикова явно мучает совесть, даже там, где он достиг идеального ландшафта, и поэтому последняя строфа стихотворения дает совсем фантасмагорическое описание, где терновник, который должен быть отождествлен с колючей проволокой, отождествляется с самим заключенным:

$$
\begin{aligned}
& \text { но скалистою волчбою } \\
& \text { раздираемый терновник } \\
& \text { видит небо над собою } \\
& \text { словно волю - уголовник }
\end{aligned}
$$

Тем самым мы можем уточнить ту стратегию Кривулина, которая уже рассматривалась как преодоление абсурдизма путем установления вертикали между небесным и земным ландшафтом [6, с. 22], такое и преодоление, и новое усвоение может идти и по горизонтали. Другая попытка изобразить юг у Кривулина - своеобразная танка «Эхо в горах» того же года: эхо в горах

это от голоса крови

дыбом встает каменный этнос

дымом черным пятнает

белые облака

При, казалось бы, простой метафоре памяти о кровавых событиях и о военных действиях, которые были в этих краях в последние столетия, очевидно, что здесь речь идет о двойной смене оптики: мы видим, как именно ландшафт оказывается устойчивым, несмотря на все военные испытания, но потом, уже изнутри этой устойчивости, мы понимаем, что память о погибших нас сопровождает. Мы уже смотрим как бы глазами вечности, совершая вечную память, и если северный ландшафт может выступать в качестве образа вечности метафорически, то здесь происходят скачки, преодолевающие границы лирических жанров. Собственно, метафор здесь нет, или эти метафоры стертые, как «голос крови», но есть представление о динамике неожиданных эффектов, которое требует лирический «голос крови» перевести в эпический регистр «каменного этноса». Читатель, чтобы избежать фантомной опасности, это делает, и в результате участвует в поминании.

В стихотворении Кековой «Щебечут птицы в облаках то на латыни, то на греческом...» (1999) противопоставление сюрреалистически изображенных Индии со «снующими, как рыбы, рикшами» и Скандинавии как ледяной Вальгаллы разрешается образом Придонья, названного античным словом Танаис:

$$
\begin{aligned}
& \text { здесь, на моей погибшей родине } \\
& \text { китовый ус, китайский рис, базар, } \\
& \text { поющий и щебечущий, } \\
& \text { и темно-желтый Танаис, } \\
& \text { на берег рыбьи шубы мечущий. }
\end{aligned}
$$

Образ реки, обильной рыбой, венчает образность базара как места одновременно покупок и продаж, а значит, не только обретений, но и утрат и гибели. Щебет базара противопоставляется молчанию и жертвенности рыб. Метание рыбы на берег, образ обильного улова соотносится с метанием икры как выражением предельной беспечной щедрости 
природы. Эта щедрость увидена уже метафизически: чешуя названа «шубой» не только из-за общей метафоричности стихотворения, но и благодаря выражению «рыбий мех», в смысле скудости, скудной лепты от всего сердца.

Изображение Придонья как места, где есть не только «базар», но и особое сочетание скудости и обилия, продолжается в финале стихотворения:

А птицы движутся на юг разноязыким человечеством -

и нет ни памяти, ни мук,

и нет вины перед отечеством, и нет ни дома позади, ни кладбища, ни поля бранного,

а только плач и боль в груди от звука низкого, гортанного...

Понять это четверостишия можно только исходя из сквозной метафоры всего стихотворения - языка птиц как понятного только мудрецу, такому как Соломон (в соответствующих восточных преданиях и сказках). Птицы в начале стихотворения и оказываются в этом арабо-персидском мире, «в богатом городе купеческом», и там они могут говорить на разных языках. Но движение с юга на север, к лирическому повествователю, уносит весь говор людской «с легким шелестом» в небеса. Чтобы начать говорить, требуется движение с севера на юг, но слов пока не находится и если в начале сообщалось о легкости звучания в небесах торгового города, то на севере «плач и боль в груди» тяжелы еще до того, как предметы горечи и скорби названы. Тогда южная природа - это природа, предназначенная для всего человечества, потому что именно там прозвучит настоящая речь, не речь скорби, но и не речь легкости. В условной Индии «брошены обрывки фраз», в условной Скандинавии - только холод, не позволяющий сказать ни слова, тогда как Придонье, «погибшая родина», место утрат, знакомит не с подобиями, а с подлинностью, с настоящими рыбами и продуктами, а не с мелькающими вслед за фразами сравнениями.

Сходная программа реализуется и в других стихах Кековой, опубликованных в том же
1999 году. Так, стихотворение «Древесные птицы и гады морские...» начинается с пейзажа охоты и птицеловства, напоминающего о декоративных полотнах и гобеленах с соответствующими сценами:

Древесные птицы и гады морские! Напялил народ колпаки поварские и ждет: птицеловы расставят силки, в кипящее море войдут рыбаки и бросят тяжелые крепкие снасти, и будут ныряльщики в устье реки сомов теребить за усатые пасти.

Перед нами экфрасис несуществующей картины, обладающий такими необходимыми свойствами этого жанра, как описание сразу нескольких действий, производимых одними лицами в одном пространстве, внимание к самым тонким деталям, к самым незаметным подробностям, которые даже не разглядеть на картине. Всё это отличает классический экфрасис как создание в речи ожившей картины. Далее идет гротескный экфрасис уже условного натюрморта, натуралистическим описанием вивисекции напоминающий о наследии поэтов группы ОБЭРИУ («Таракан» Н. Олейникова):

Доставлена будет добыча к столу, и повар возьмет поварскую иглу и сердце нащупает пойманной твари, проколет его; небольшую пилу наточит, о Божьей не думая каре, распилит убитых животных тела, огромную печь раскалит добела.

И, наконец, в середине стихотворения появляется река, текущая на юг:

Ползите скорей, муравьи и жуки, летайте, стрекозы, по белому свету, лежите, ракушки, под илом реки, текущей на юг и впадающей в Лету.

Перечисление муравьев и жуков уже напоминает не об Олейникове, а о другом обэриуте - Заболоцком («Поет синклит беззвучных насекомых»). Если предыдущие строфы изображали безмолвный крик, несущийся 
с картин, то эта строфа изображает истинное природное безмолвие, которое и осуществляется на юге, как уже легкость забвения и одновременно всемирное спасение, когда возможно летать по всему белому свету. В последней части стихотворения весь этот мир дается глазами насекомого, уже взглядом из иного мира. В другом стихотворении, «Злая зима в этом тысяча мертвом году», Кекова изображает тяжелую зиму, которую отождествляет и с монгольским игом, и с истязаниями и скорбями христианских мучеников. В предпоследней строфе вспоминается юг:

$$
\begin{aligned}
& \text { Видела я удивительно явственный сон: } \\
& \text { вышел январь в раскаленной } \\
& \text { железной кольчуге, } \\
& \text { голову вскинул - и выстрелил }
\end{aligned}
$$$$
\text { в облако он, }
$$

родину вспомнив,

заплакали птицы на юге.

Образ выстрела в облако понятен, только если обратиться к поэзии Арсения Тарковского, для которого «облако» и «яблоко» образовывали устойчивую пару, раскрывающую природу чувственного восприятия, полусновидческого, полуреального:

Слышу круглого яблока круглый язык, Слышу белого облака белую речь

(«Я прощаюсь со всем, чем когда-то я был...»)

Тогда выстрел в облако на переходе от сна в явь соответствует выстрелу в яблоко, проверке меткости или риску. Но тогда и обычная метафора мечты, мечты северной природы о южной, которую мы помним все из Гейне и перевода Лермонтова («На Севере диком стоит одиноко...) переворачивается: птицы не мечтают о севере, а плачут, тяжело переживают. Таким образом, южная природа оказывается местом, в котором воспоминания оказываются особого качества, не воспоминанием о былом, но точным, метким попаданием образа в то, что происходит в других краях.

Вместе с тем у Кековой, несмотря на то что горы - ее родина и юг поэтому не может быть частью оппозиции горного раз- нообразия и равнинного однообразия, есть тоже ландшафт юга и природного наследия, в стихотворении «На усталой коже оставив метку» (1999). В первых строфах представляя личные переживания («покидает птица грудную клетку»), далее стихотворение переходит в тот самый образ рыб, который и вводит уже не просто южные ландшафты, а южные пейзажи, узнаваемые по своей яркости (ночное благоухание трав, пастух с овцами, морская звезда южных морей):

соловей, возносящий молитвы Богу,то забытую он пропоет эклогу, то в беспамятстве свищет свои псалмы. Рыб горбаты спины. Земли холмы

расцветают ночью травой узорной. Мокнут сети ловчие. Спит ловец, и пастух, бредущий травою горной, ищет стадо заблудших своих овец.

Я уже не плачу и не тоскую, наудачу славлю звезду морскую, твоего убежища свет туманный, где мой сон скитается безымянный.

После такого изображения многочисленных примет южного природного наследия мы все же находим образ северной тяжести, но уже осмысленный не как ландшафтный, а как произведенный и этическим выбором, между правдой и ложью, и литературным выбором, перед «пустой страницей»:

А в своем отечестве, на границе безымянной правды и старой лжи, как слова на белой пустой странице, в равнодушном небе снуют стрижи.

Фактически речь идет об историческом переживании, но уже после райского опыта юга, причем не о сожалении или сочувствии, но о новом эксперименте, насколько литературный опыт вообще может схватывать исторический опыт. Противопоставление южной легкости и северной тяжести, каковы бы ни были его истоки в русской поэтической традиции, в религиозно-метафизической поэзии становится не предметом лирического 
созерцания, а поводом для разговора о смысле и содержании истории. Так, в стихотворении «На руинах межрайонного дома дружбы» (1995) Кривулин противопоставляет «кавказ полувоздушный» (поздний Кривулин часто отказывается от прописных букв, превращая все имена как бы в нарицательные слова), легкость той тяжести северной жизни, которую олицетворяет стоящий в городе на Неве дом дружбы - трактор на фреске кажется повествователю тяжело чихнувшим и заглохшим, а вовсе не торжественным апофеозом радостного труда, как задумывал вымышленный автор фрески.

Таким образом, проведенное исследование показало, что хотя предпосылки этих поэтов различны, они создают общую концепцию природного наследия юга России. Предпосылки их различаются прежде всего исходным опытом родного ландшафта: для Кривулина это однообразный северный пейзаж, а для Кековой - ландшафтное разнообразие Поволжья. При этом противопоставление северной и южной природы поддерживается у них не только ландшафтными наблюдениями, но и институционально, вниманием к тем ин- ституциям, которые стали возможны в мире природы юга России. Это не только современные институции, как курорты, но и древние, такие как астрономические наблюдения.

Природное наследие юга России в поэзии этих авторов раскрывается не статически, а динамически, в связи с религиозным экзистенциальным пониманием человеческой жизни. Такие устойчивые признаки южной природы, как обилие, видовое разнообразие и возможность широкого обзора, оказываются символами для интерпретации мистического опыта приобщения к другой оптике. Если север аскетичен, то юг идилличен, и эта идилличность раскрывается как возможность оптики рая во взгляде на современную социальную жизнь. В жанровой системе этих поэтов происходит двойная конвертация: образность юга России благодаря культурным ассоциациям начинает напоминать райскую образность, а появление экзистенциальной проблематики благодаря противопоставлению севера и юга позволяет воспринять эту странную образность как естественную, как от природы ожидаемую душой, перейдя к более глубокому чувству родины.

\section{Alexander V. MARKOV \\ The Natural Heritage of Southern Russia in the Poems by Viktor Krivulin and by Svetlana Kekova}

Abstract. In the works of the leading Russian poets of the religious-metaphysical trend, nature appears as both the object of lyrical reflections and a landscape, which serves as an occasion for reflection on the realised and unrealised. Natural landscapes are perceived within the genres of painting, and their lyrical contemplation contributes to the renewal of the genre system of poetry. The poems by Viktor Krivulin and by Svetlana Kekova were selected for the study; their common features are a deep knowledge of religious and philosophical traditions, a general orientation to the heritage of Russian symbolism, avant-garde and absurdism, the desire for permeability of different lyrical genres and, therefore, the absence of a distinct landscape lyrics. Reflections on landscape are embedded here in reflections on the existential purpose, and the nature of southern Russia is revealed as part of an existential choice. A close reading was chosen as the research method, with contextualisation of the material based on the sustainable cultural images of Russia's southern nature in the culture. Religious-metaphysical poetry always pays attention not only to nature as such, but also to its iconicity, to its reflection in the canonical forms of landscape or ekphrasis. The intense reflection on the role of southern nature in Russian culture is demonstrated in Krivulin's and Kekova's poems through an unusual paradoxical combination of its various "icons", canonically enshrined in the traditional imagery. The research has shown that, although the poets' prerequisites are different, they create a common concept of the natural heritage of southern Russia. Their prerequisites differ, first of all, in the original experience of the native landscape: for Krivulin, it is the homogeneous northern landscape; for Kekova, it is the landscape diversity of the Volga region. At the same time, the juxtaposition of northern and southern nature is supported not only 


\begin{abstract}
by landscape observations, but also institutionally, by attention to institutions that have become possible in the natural world of southern Russia. These are not only modern institutions, like resorts, but also ancient ones, such as astronomical observations. The conclusion of the article is that the natural heritage of the south of Russia in the poems by these authors is revealed dynamically rather than statically, in connection with the religious existential understanding of human life. Such persistent features of southern nature as abundance, species' diversity and a wide panorama are symbols for interpreting the mystical experience of joining a different optics. If the north is ascetic, then the south is idyllic, and this idyll is rethought as a possibility of paradise optics in the view of today's social life.
\end{abstract}

Keywords: landscape, landscape lyrics, ekphrasis, imaginary, iconicity, poetic imagination, southern nature, southern Russia, religious metaphysics.

\section{Использованная литература:}

1. Григорук С. И. Концепт синего цвета в поэзии Георгия Иванова // Культура народов Причерноморья. 2003. № 44. С. 125-129.

2. Замятин Д. Н. Империя пространства: Географические образы в романе А. Платонова «Чевенгур» // Вопросы философии. 1999. Т. 10. С. 82-89.

3. Зверева Т. В. Имперский миф: от классицизма к модернизму // Вестник Удмуртского университета. Серия «История и филология». 2018. Т. 28. №. 3. С. 313-322.

4. Колотаев В. А. Фотоискусство как система поэтически эксплицируемых репрезентаций //Артикульт. 2017. №. 1(25). С. 18-31.

5. Лучина Е. И. Функции грецизмов православного религиозного дискурса в художественном тексте (на материале поэзии С. В. Кековой) // Известия Саратовского университета. Новая серия. Серия «Филология. Журналистика». 2009. Т. 9. №. 3. С. 55-60.

6. Павловец М. О стихотворении В. Кривулина «Хлопочущий Иерусалим»: литературоведческий комментарий к комментарию лингвистическому // Полилог. 2011. Т. 4. С. 19-25.

7. Седакова О. Другая поэзия // Новое литературное обозрение. 1996. № 22. С. 233-242.

8. Тальских Т. С. Иконические мотивы в современной поэзии духовной традиции (на материале лирики С. Кековой, О. Николаевой, О. Седаковой, О. Василия (Рослякова)) // Известия Волгоградского государственного педагогического университета. 2016. №. 5 (109). С. 134-140.

\section{References:}

1. Grigoruk, S.I. (2003) Kontsept sinego tsveta v poezii Georgiya Ivanova [The Concept of Blue in the Poetry of Georgiy Ivanov]. Kul'tura narodov Prichernomor'ya. 44. pp. 125-129.

2. Zamyatin, D.N. (1999) Imperiya prostranstva: Geograficheskie obrazy v romane A. Platonova "Chevengur" [Empire of Space: Geographical Images in A. Platonov's Novel "Chevengur"]. Voprosy filosofii. 10. pp. 82-89.

3. Zvereva, T.V. (2018) Imperial Myth: From Classicism to Modernism. Vestnik Udmurtskogo universiteta. Seriya "Istoriya i filologiya" - Bulletin of Udmurt University. Series History and Philology. 28 (3). pp. 313-322. (In Russian).

4. Kolotaev, V.A. (2017) Art of Photography as System of Poetically Explained Representations. Artikul't - Articult. 1(25). pp. 18-31. (In Russian).

5. Luchina, E.I. (2009) The Functions of Greek Loanwords of the Orthodox Religious Discourse in Literature (On the Material of S.V. Kekova's Poetry). Izvestiya Saratovskogo universiteta. Novaya seriya. Seriya "Filologiya. Zhurnalistika" - Proceedings of Saratov University. Ser. Philology. Journalism. 9(3). pp. 35-40. (In Russian).

6. Pavlovets, M. (2011) 0 stikhotvorenii V. Krivulina "Khlopochushchiy Ierusalim": literaturovedcheskiy kommentariy $\mathrm{k}$ kommentariyu lingvisticheskomu [On V. Krivulin's Poem "Bustling Jerusalem": A Literary Commentary on the Linguistic Commentary]. Polilog. 4. pp. 19-25.

7. Sedakova, O. (1996) Drugaya poeziya [A Different Poetry]. Novoe literaturnoe obozrenie - New Literary Observer. 22. pp. 233-242.

8. Tal'skikh, T.S. (2016) Iconic Motives in the Modern Poetry of the Spiritual Tradition (Based on the Lyrics by S. Kekova, O. Nikolaeva, O. Sedakova, Father Vasily (Roslyakov)). Izvestiya Volgogradskogo gosudarstvennogo pedagogicheskogo universiteta - Ivzestia of the Volgograd State Pedagogical University. 5 (109). pp. 134-140. (In Russian).

\footnotetext{
Полная библиографическая ссылка на статью:

Марков А. В. Природное наследие Юга России в поэзии Виктора Кривулина и Светланы Кековой [Электронный ресурс] / А. В. Марков // Наследие веков. - 2019. - № 4. - С. 19-27. DOI: 10.36343/SB.2019.20.4.002
} vekov - Heritage of Centuries. 4. pp. 19-27. (In Russian). DOI: 10.36343/SB.2019.20.4.002 